\title{
Ocular manifestation in Rheumatoid arthritis and Juvenile rheumatoid arthritis
}

Kumar $\mathbf{P}$

Prajjwal Kumar, Teaching Assistant, BP Koirala Lions Centre for Ophthalmic Studies, Kathmandu, Nepal.

\section{ABSTRACT}

Background: Rheumatoid arthritis (RA) and juvenile rheumatoid arthritis (JRA) are systemic autoimmune diseases characterized by synovitis and a wide range of extra articular manifestations. Ocular involvement occurs frequently in both diseases and it may affect all layers.

Objectives: To identify different types of ocular involvement in cases of Adult Rheumatoid Arthritis (RA) and Juvenile Rheumatoid Arthritis (JRA) in a tertiary care hospital in Nepal and to compare the prevalence of those ocular findings among them.

Methods: In this hospital based cross-sectional study, all cases referred from Orthopaedics department, Paediatrics department, Internal Medicine Rheumatology clinic of Kanti Children Hospital presenting to the OPD of BP Koirala Lions Centre for Ophthalmic Studies (BPKLCOS), cases admitted in eye ward and orthopaedics ward from 1st February 2009 to 31 st July 2010 were included. Patients below 15 years of age were included in Juvenile Arthritis group. Detailed systemic and ocular history was taken as per the proforma and detailed ocular examination was carried out. Paired t-test was used as the statistical tool to find out the significant difference.

Results: Among 50 cases included in the study the cases of Rheumatoid Arthritis were $32(64 \%)$ and Juvenile Rheumatoid Arthritis were 18 (36\%). In the study, females (32) were predominant as compared to males (18). In RA group females predominated whereas in JRA group males predominated. Among 50 cases of arthritis 33 cases showed ocular involvement ( 25 from RA group and seven from JRA group). Among them, the most common ocular manifestation was dry eye $22 \%$ (mild, moderate and severe forms) followed by uveitis nine percent, corneal ulcers two percent, viral keratitis two percent, conjunctivitis two percent, episcleritis one percent and glaucoma one percent. Conclusion: Cases of Rheumatoid Arthritis and Juvenile Rheumatoid Arthritis should be subjected to regular ocular evaluation because of possibility of ocular involvement due to disease itself or the medication being used to treat them. Ocular manifestations due to RA and JRA are not uncommon in our population thus early identification of the disease and their proper management would possibly prevent visual loss in the majority of the cases.

Key words: Juvenile Rheumatic Arthritis, RA factor, Rheumatic Arthritis

\section{INTRODUCTION}

Rheumatoid arthritis (RA) and juvenile rheumatoid arthritis (JRA) also known as Juvenile Idiopathic Arthritis $(\mathrm{JIA})^{1}$ are systemic autoimmune diseases characterised

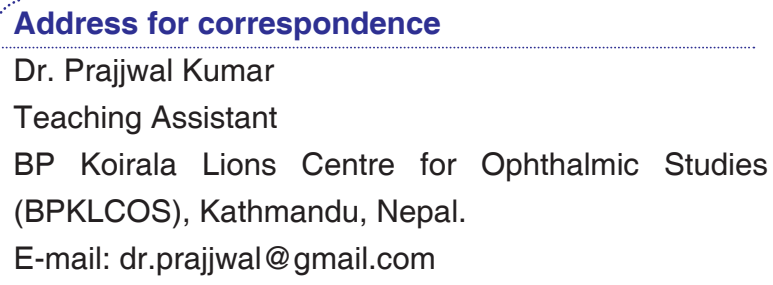

by synovitis and a wide range of extra-articular manifestations. Ocular involvement occurs frequently in both diseases and it may affect all layers of eye ${ }^{2}$.

Rheumatoid arthritis has a worldwide distribution with an estimated prevalence of one to two percent ${ }^{3}$. Prevalence increases with age, approaching five percent in women over the age $55^{3}$. Both incidence and prevalence of rheumatoid arthritis are two to three times greater in women than in men. Although rheumatoid arthritis may present at any age, patients most commonly are first affected in the third to sixth decades. The common ocular 
findings of rheumatoid arthritis are keratoconjunctivitis, anterior uveitis, episcleritis, necrotising nodular scleritis, and scleromalacia perforans ${ }^{4}$. The cumulative incidence of uveitis in JIA has been reported between $8.5 \%$ and $25 \%$ in series from referral centres around the world ${ }^{1}$ and is a common cause of visual morbidity in children. Arthritis typically precedes the onset of uveitis ${ }^{1}$. The most common ocular inflammation in JRA is white eye with chronic anterior uveitis, long standing case may present with band keratopathy of cornea and complicated cataract $^{5}$. It is noteworthy that they may precede the articular symptoms by several months to years. Juvenile rheumatoid arthritis accounts for approximately 80 percent of cases of uveitis in children ${ }^{6}$. Delay in diagnosis can lead to cataracts, glaucoma, and blindness.

Regardless of their variable occurrence, these diseases are responsible for marked number of disability and morbidity throughout the world. Furthermore, the ocular involvement can lead to lifelong complication resulting in visual impairment and sometimes even blindness. Beside the disease, Disease-modifying antirheumatic drugs (DMARDs) particularly choloroquine can also effect vision by deposition over the macula and cornea.

The importance of early diagnosis of ophthalmic disease in patients with RA cannot be overemphasized since it permits the timely management of potentially serious sight-threatening complications. The presence of ocular disease may also be an indication of on-going systemic disease activity ${ }^{7}$. Not infrequently, the cases of aforementioned arthritis are referred to when the disease is in advanced stages and vision has been greatly affected. A study of this nature in our set up can suggest the physician managing the arthritis to refer the cases as early as possible for early detection of ocular complication, thus helping in minimising oculovisual problems in these cases by early ophthalmic interference, if that is needed.

The general objective of this study was to identify different types of ocular involvement in cases of Adult Rheumatoid Arthritis and Juvenile Rheumatoid Arthritis (JRA) in a tertiary care hospital in Nepal. Other objectives were to study age and sex distribution of the patients and to compare the prevalence of the ocular findings in RA and JRA.

\section{METHODS}

This cross-sectional 18 month study was conducted at BP Koirala Lions Centre for Ophthalmic Studies from $1^{\text {st }}$ February 2009 to $31^{\text {st }}$ July 2010. Cases referred from Orthopaedics Department, Paediatrics department of Tribhuvan University Teaching Hospital (TUTH), Internal Medicine Rheumatology Clinic of Kanti Children Hospital $(\mathrm{KCH})$, admitted cases in Eye ward and Orthopaedics ward were included in this study.

The inclusion criteria consisted of all seropositive Rheumatoid arthritis cases and cases of Juvenile Rheumatoid arthritis irrespective of seropositivity.

The exclusion criteria comprised of seronegative Rheumatoid arthritis, infective arthritis and patients who did not wish to be included in the study.

Clinical Assessment: Detailed systemic and ocular history was taken as per the proforma and likewise detailed ocular examination was carried. Visual Acuity was evaluated using Snellen chart for literate and $E$ chart for illiterate patients. In children where subjective results were unobtainable or unreliable, Catford drum was used. Extraocular movement, cover test, examination of lid and adnexa were performed with help of torchlight. Conjunctiva, episclera, sclera and anterior segment were examined using Haag Streit 900 slit lamp. In the cases of suspected episcleritis and scleritis diffuse natural light was also used for evaluation.

For the evaluation of cells in the anterior chamber, the widest slit lamp beam at $1.00 \mathrm{~mm}$ height with maximum luminance of Haag-Streit slit lamp was used. Grading of cells and flare in the anterior chamber was done according to Hogan's classification ${ }^{8}$ (Table 1 and 2). Vitreous opacities were evaluated with slit lamp and graded with direct ophthalmoscope according to Hogan's classification $^{8}$ (Table 3). Fundus was examined after the full dilatation of pupil, the fundus examination was carried out with direct ophthalmoscope Heine Beta 200, and with indirect ophthalmoscope and $+90 \mathrm{D}$ lens and +20 $D$ lens in selected cases, wherever it was felt necessary. Intraocular pressure was taken by Goldman applanation tonometer using slit lamp biomicroscope. 
Table 1: Grading of cells in anterior chamber.

\begin{tabular}{ll}
\hline Cells per field & Grade \\
0 & No cells \\
$1-2$ & Rare cells \\
$3-7$ & Occasional cells \\
$7-10$ & $1+$ cells \\
$10-20$ & $2+$ cells \\
$20-50$ & $3+$ cells \\
$>50$ & $4+$ cells \\
\hline
\end{tabular}

Table 2: Grading of flare in anterior chamber.

\begin{tabular}{lc}
\multicolumn{1}{c}{ Flare } & $\begin{array}{c}\text { Grade } \\
\text { No flare }\end{array}$ \\
0 & $1+$ \\
Faint flare (barely detectable) & $2+$ \\
Moderately (iris and lens detail clear) & $3+$ \\
Marked flare (iris and lens detail hazy) & \\
Intense flare (fixed coagulated aqueous & \\
humour with considerable fibrin) & $4+$ \\
\hline
\end{tabular}

Table 3: Grading of vitreous opacity.

\begin{tabular}{lc} 
Vitreous Haze & Grade \\
No opacities & 0 \\
\hline Few opacities but fundus clearly seen & $1+$ \\
\hline $\begin{array}{l}\text { Scattered fine and coarse opacities } \\
\text { with somewhat obscured fundus }\end{array}$ & $2+$ \\
\hline Many opacities with marked blurring of fundus & $3+$ \\
Dense opacities prevent a view of the fundus & $4+$ \\
\hline
\end{tabular}

Investigations: Schirmer's test I and II was performed in each and every case. Investigations regarding the course of arthritis were reviewed thoroughly:

- Blood- Total count, Differential count, Haemoglobin, Erythrocyte Sedimentation Rate, Rheumatoid Factor,

- Antinuclear antibody test.

- X-rays of the involved joint.

Other pertinent investigations like Computed tomography and Magnetic Resonance Imaging of head and orbit were done as and when necessary.

Consultations with other medical specialties were sought in cases wherever it was felt necessary
Statistical Analysis: All the data was analyzed using the software SPSS version 17 .

\section{RESULTS}

Among 50 cases included in the study the cases of Rheumatoid Arthritis were 32 (64\%) and Juvenile Rheumatoid Arthritis were 18 (36\%) In the study, female were predominant as compared to males (32 versus 18 ), Table 4.

Among total 50 cases of arthritis patients $33(66 \%)$ cases showed ocular involvement: 25 out of $32(78.13 \%)$ patients in RA group and eight out of 18 (44.44\%) in JRA group (Table 5). Out of those 33 cases, only 17 had ocular symptoms while 16 were asymptomatic.

Among 25 RA patients with ocular involvement, highest number of patients [nine $(36 \%)$ ] was seen in $5^{\text {th }}$ decade followed by seven cases (28\%) in the sixth decade, three cases $(12 \%)$ each in third and fourth decade. The least number [two (4\%)] was seen in $8^{\text {th }}$ and $2^{\text {nd }}$ decade. Among eight patients of Juvenile Rheumatoid Arthritis with ocular involvement, three were males and five were females, six of them presented in the age group 11-15 years, and one each in age group 6-10 and 0-5 respectively.

Table 6 shows different types of ocular involvement in Rheumatoid arthritis and Juvenile rheumatoid arthritis. Among 33 cases with ocular involvement the most common ocular manifestation was dry eye (mild, moderate and severe forms) followed by uveitis, corneal ulcers, viral keratitis, conjunctivitis, episcleritis and glaucoma.

Most commonly occurring ocular problem in patient with Rheumatoid arthritis was dry eyes (59.37\%), followed by uveitis $(15.6 \%)$, viral keratitis, conjunctivitis, corneal ulcers $(6.25 \%)$ respectively. Out of 25 cases of RA with ocular involvement, seven cases had multiple ocular involvement, six cases had two ocular complications while one case had four different types of ocular complication like dry eye, conjunctivitis, viral keratitis, and corneal ulcer. This patient suffered from corneal perforation and ultimately underwent evisceration.

Among eight JRA patients with ocular involvement four patients had Uveitis, three had dry eye and one 
case episcleritis. Table 7 shows different forms of Juvenile rheumatoid Arthritis. Polyarticular form was the commonest (50\%).

Analysis of serological factors in JRA patients showed that four out of 18 cases $(22.22 \%)$ had positive RA factor while eight (44.44\%) were ANA positive.

One of the causes of diminution of vision among 33 cases with ocular disease was refractive error. In our study group 17 patients had refractive error. Among 17 patient 14 cases had other ocular involvement with refractive error and three had only refractive error.

Table 8 and 9 show duration of joint problems in two study groups.
Table 4: Age and sex distribution of the study group

\begin{tabular}{|lcc|}
\hline $\begin{array}{l}\text { Age range } \\
\text { Juvenile Rheumatic Arthritis }\end{array}$ & Female \\
\hline $0-5$ & 1 & \\
\hline $6-10$ & 3 & 1 \\
$11-15$ & 6 & 3 \\
\hline Total & 10 & 4 \\
\hline Rheumatic Arthritis & & 8 \\
\hline $16-20$ & 0 & \\
\hline $21-30$ & 2 & 1 \\
\hline $31-40$ & 0 & 1 \\
\hline $41-50$ & 4 & 8 \\
\hline $51-60$ & 1 & 5 \\
\hline $61-70$ & 0 & 8 \\
\hline 70 & 1 & 1 \\
\hline Total & 8 & 0 \\
\hline
\end{tabular}

Table 5: Ocular involvement in Rheumatoid arthritis and Juvenile Rheumatoid Arthritis.

\begin{tabular}{cccccccc}
\hline & & \multicolumn{2}{c}{ Rheumatoid Arthritis } & \multicolumn{2}{c}{ Juvenile Rheumatoid Arthritis } & Total \\
& & Male & Femal & Male & Femal & \\
Ocular Involvemnt & Present & 8 & 17 & 3 & 5 & 33 \\
& Absent & 0 & 7 & 7 & 3 & 17 \\
\hline
\end{tabular}

Table 6: Different types of ocular involvement in Rheumatoid arthritis and Juvenile Rheumatoid Arthritis

\begin{tabular}{|c|c|c|c|c|c|}
\hline \multirow[t]{2}{*}{ Disease pattern } & \multicolumn{2}{|c|}{ Rheumatoid arthritis } & \multicolumn{2}{|c|}{ Juvenile Rheumatoid arthritis } & \multirow[t]{2}{*}{ Tota } \\
\hline & Total & Percentage & Total & Percentage & \\
\hline Dry eye & 19 & 38 & 3 & 6 & 22 \\
\hline Uveitis & 5 & 10 & 4 & 8 & 9 \\
\hline Episcleritis & 0 & 0 & 1 & 2 & 1 \\
\hline Scleritis & 0 & 0 & 0 & 0 & 0 \\
\hline Corneal ulcer & 2 & 4 & 0 & 0 & 2 \\
\hline Band keratopathy & 0 & 0 & 0 & 0 & 0 \\
\hline Viral keratritis & 2 & 4 & 0 & 0 & 2 \\
\hline Interstitial keratitis & 0 & 0 & 0 & 0 & 0 \\
\hline Conjunctivitis & 2 & 4 & 0 & 0 & 2 \\
\hline Glaucoma & 1 & 2 & 0 & 0 & 1 \\
\hline Others & 4 & 8 & 0 & 0 & 4 \\
\hline Total & $35^{*}$ & & 8 & & 43 \\
\hline
\end{tabular}

*35 patients with Rheumatoid arthritis include 6 patients with two different type of ocular involvement and 1 patient had four different type of ocular involvement. Hence, numbers of patients were only 25 making the disease affliction 35. 
Table 7: Different form of Juvenile Rheumatoid Arthritis noted in the study group.

\begin{tabular}{lccc|}
\hline Form of JRA & Male & Female & Total \\
\hline Pauciarticular & 3 & 2 & 5 \\
Polyarticular & 4 & 5 & 9 \\
Systemic & 3 & 1 & 4 \\
Total & 10 & 8 & 18 \\
\hline
\end{tabular}

Table 8: Duration of arthritis in patients with Rheumatoid Arthritis

\begin{tabular}{|cc|}
\hline Duration (in years) & Number \\
\hline$<1$ & 7 \\
$1-5$ & 17 \\
$6-10$ & 7 \\
$11-15$ & 0 \\
\hline $16-20$ & 0 \\
\hline 20 & 1 \\
\hline
\end{tabular}

Table 9: Duration of arthritis in patients with Juvenile Rheumatoid Arthritis

\begin{tabular}{lc}
\hline Duration (months) & Number \\
\hline$<6$ & 4 \\
$6-12$ & 5 \\
$12-24$ & 9 \\
$>24$ & 0 \\
\hline & 18 \\
\hline
\end{tabular}

\section{DISCUSSION}

The prevalence of Rheumatoid and Juvenile Rheumatoid Arthritis has regional variation. The incidence of rheumatoid arthritis in populations of northern European origin is $20-300$ per 100,000 per year ${ }^{9}$. The disease prevalence is about one percent in Caucasians, but varies between 0.1 percent (in rural Africans) and five percent (in Pima and Chippewa Indians) ${ }^{10}$. According to Kelly Harris et al the worldwide prevalence of Rheumatoid arthritis is suspected to be $1-3 \%$ of general population and the working prevalence of juvenile Rheumatoid arthritis is $10-20 / 100,000$ population ${ }^{11}$.
Rheumatoid arthritis has a predilection for women by a ratio of $3: 1^{12}$ and onset of clinical disease is in fourth and fifth decades. In our study too females were predominant compared to males.

According to S.C. Reddy et $\mathrm{al}^{13}$ out of 100 patients of RA 39\% had ocular involvement. The prevalence of different ocular manifestations in this arthritis has been reported differently in different studies. The result of the present study showed, 33(66\%) cases out of 50 with ocular involvement and $17(34 \%)$ cases without ocular involvement.

The prevalence of ocular manifestation was found to be higher in Rheumatoid arthritis $(78.12 \%)$ as compared to Juvenile rheumatoid Arthritis (44.44\%) which is comparable to previous study ${ }^{14}$ done at this centre where ocular manifestation was found to be highest in RA (43.41\%) among all the other non-infective arthritis.

Patient with arthritis with ocular involvement may not have ocular complaints as such but when ocular examination was carried out, positive findings were detected. Out of 33 cases with ocular involvement $51.5 \%$ cases had symptom while $49.5 \%$ did not have any symptom, while the previous study ${ }^{14}$ showed only $37.28 \%$ complained of ocular symptom. Such disparities are not uncommon in different studies done at different times and places.

Among 3,722 individual studied by Moss S.E. ${ }^{15}$ he found $14.4 \%$ of patients with dry eyes. Dry eyes were found to be more common in females (16.7\%) than in males (11.4\%). The risk factor for developing dry eye in first place was arthritis followed by gout. In our study the most common ocular manifestation among all cases with arthritis was dry eye $44 \%$ (22 cases), followed by uveitis $(18 \%)$, episcleritis (2\%), and corneal ulcer, viral keratitis, and conjunctivitis.

The onset of clinical disease in Rheumatoid Arthritis is usually in fourth and fifth decades and has a predilection for women by the ratio $3: 1$. In our study too majority of the patient with Rheumatoid Arthritis where in their fifth and sixth decades which comprised 56\% (18 cases) with female predominance 3:1. Among 25 cases of Rheumatoid Arthritis with ocular involvement, the highest incidence of ocular manifestation was also seen in the fifth decade i.e. in nine (36\%) cases. 
Keratoconjunctivitis Sicca or dry eye is the most common ocular manifestation of Rheumatoid Arthritis with reported prevalence of $15-25 \%{ }^{16}$. In juvenile Rheumatoid Arthritis it remains underreported. Jain $\mathrm{V}$, Singh $\mathrm{S}^{17}$ et al conducted a study with 50 Juvenile Rheumatoid Arthritis, Seven of which (14\%) were diagnosed as having Keratoconjunctivitis Sicca proving that Keratoconjunctivitis Sicca is not uncommon with Juvenile Rheumatoid Arthritis patients.

Kaisu M Kotaniemi, et al, from Rheumatism Foundation Hospital, Heinola, Finland evaluated total of 192 children with JIA and found that Dry eye symptoms and signs are common in $\mathrm{JIA}^{18}$. In their study $17 \%$ of had decreased basal tear secretion. In our study, the prevalence of dry eye in patients with Rheumatoid Arthritis was 76\% and in 18 cases of Juvenile Rheumatoid Arthritis only three (16.66\%) had mild form of dry eyes.

A prospective study was conducted by Watson and Hayreh ${ }^{19}$ which included 207 patients with episcleritis and 159 patients with scleritis with a follow up of 10 years. Rheumatoid arthritis was found in 28 patients in their study group. Seven (25\%) out of 28 were with episcleritis, eight (28.57\%) with diffuse anterior scleritis, four (14.29\%) with nodular anterior scleritis, three $(10.71 \%)$ with necrotizing scleritis and six $(21.43 \%)$ with scleromalacia perforans.

Douglas A. Jabs et al, at Departments of Ophthalmology and Medicine, the Johns Hopkins University School of Medicine, Baltimore, Maryland ${ }^{20}$ studied one hundred thirty-four patients with scleral inflammation over a 12 year period. Out of 134 patients thirty-seven patients had episcleritis, and 97 patients had scleritis. Nearly $30 \%$ of patients with episcleritis and $39.2 \%$ of the patients with scleritis had an associated systemic rheumatic disease. The rheumatic disease most commonly associated with scleral inflammation was rheumatoid arthritis.

In our study, 25 patients out of 32 patients with Rheumatoid arthritis were with ocular involvement; among them none had episcleritis or scleritis while out of eight cases of ocular involvement in Juvenile Rheuamtoid Arthritis in three (37\%) had episcleritis. Necrotizing scleritis with inflammation and scleromalacia perforans were not seen in our study. One of the causes of disparity in the incidence of episcleritis and scleritis in patients with Rheumatoid arthritis may be short duration of the study or may be due to earlier presentation of the cases for ophthalmic evaluation. In the same way, necrotizing scleritis and scleromalacia perforans; severe form of scleritis; were not noted in our study as these complicated conditions were found in patients with long duration of arthritis with severe forms and in long term untreated cases.

In a study by D. D. McGavin et al, 4210 patients with rheumatoid arthritis were examined at the Centre for Rheumatic Diseases at Tennent Institute of Ophthalmology and Southern General Hospital, Glasgow $^{21}$. Seven of these patients had episcleritis (0.17 per cent) and 28 patients had scleritis ( 0.67 per cent). Similarly they found co-existent posterior scleritis was more common in rheumatoid scleritis (22.2 per cent) than in non-rheumatoid scleritis (5.6 per cent). Another retrospective study of patients with diagnosis of posterior scleritis revealed that the patients with the age group $>50$ years had a higher risk of developing an association of systemic disease and in that particular study was found to be Rheumatoid Arthritis, while in our study, among the patients with Rheumatoid Arthritis, none was found to have posterior scleritis.

Uveitis is a rare ocular manifestation of Rheumatoid Arthritis whereas with Juvenile Rheumatoid arthritis it has a stronger association. In one of the prospective studies conducted by Kimura and his colleagues ${ }^{22}$ with 1,927 cases of uveitis, 191 cases revealed to have associated joint disease. Twenty three (12.04\%) patients were found to have Rheumatoid Arthritis. Patients $<16$ years of age included in this study, 14 (7.33\%) were found to have Juvenile Rheumatoid Arthritis and among the patients 16 year and older, 11 (5.76\%) patients with iridocyclitis had Juvenile Rheumatoid Arthritis. Band shaped keratopathy were noted in two of these patients with Juvenile Rheumatoid Arthritis who had their uveitis for 11 and 28 years.

Chylack LT Jr. ${ }^{23}$ followed 210 cases of JRA closely for 14 years. He found thirty-six patients (17.2\%) developed iridocyclitis; and most frequently occurred in young females (0-4 years) with monarticular or pauciarticular form of the disease. In $30 \%$ of the patients iridocyclitis was first detected after 16 years of age and forty-two percent had active iridocyclitis on entry. 
Our study revealed that among 25 patients with ocular involvement out of 32 Rheumatoid Arthritis patients only five $(20 \%)$ had anterior uveitis but band shaped keratopathy was not noted along with it. Among eight patients with ocular involvement out of 18 Juvenile Rheumatoid Arthritis patients anterior uveitis was found in four $(50 \%)$ cases but none were associated with complications such as band keratopathy or cataract.

Cases of glaucoma secondary to scleritis and episcleritis 19,21,24 have been reported in different studies. But we did not find any case with glaucoma secondary to scleral or episcleral involvement, which may be due to less number of cases in the study or the less severe form of disease noted in these patients. In our study secondary glaucoma due to uveitis was noticed in one patient with Rheumatoid Arthritis.

Different case reports have been published about the marginal furrowing ${ }^{25-28}$ associated mainly with Rheumatoid Arthritis patients, the initial cause of which frequently was the presence of Keratoconjunctivitis Sicca and in many cases they progressed to marginal ulceration, thinning and eventually perforation. In our study 2 cases with Rheumatoid arthritis had corneal ulcers. Out of the 2 cases one had peripheral corneal ulcer that had a long standing Rheumatoid Arthritis and presented to us in late stage which had perforated and ultimately lead to evisceration of that eye. The other case had a central corneal ulcer and the scrapping revealed no growth which was treated satisfactorily with topical antibiotics and mydriatics. The possible predisposing cause of corneal ulcer in this case may be due to dry eyes as indicated by Schirmer's test.

A number of studies have proved that conjunctival resection is an effective therapeutic modality for the treatment of marginal furrows associated with Rheumatoid Arthritis ${ }^{29,30}$.

Few literatures have mention about optic nerve head involvement in Rheumatoid Arthritis. Optic nerve disease after scleritis has had little documentation ${ }^{21}$. Optic disc oedema was associated with cilioretinal occlusion and was due to arteritis ${ }^{31}$. In our study one case had bilateral disc edema, no other cause was found on investigation and hence. We presume it was due to inflammatory arthritis that the patient had.
Refractive error too is one of the causes of visual impairment in arthritis patients. Our study revealed that among 33 cases with ocular involvement 17 had refractive error. Among 17 cases with refractive error 14 cases had other ocular problems, showing that specific ocular disease entities have greater role in visual impairment in the cases of arthritis than refractive error alone.

By definition Juvenile rheumatoid Arthritis begins before the age of 16 years. Girls are five times more likely than boys to have prolonged disease. Most of the studies ${ }^{1,32-}$ ${ }^{37}$ showed greater percent of patients have pauciarticular form of disease followed by polyarticualr and less is the systemic form. The ocular manifestations mainly uveitis was seen very early after the onset of arthritis, that too with pauciarticular form of disease and with Antinuclear Antibody positive patient with preponderance in young females. Young age is a greater risk factor for developing uveitis in Juvenile Rheumatoid Arthritis.

Our study also showed that highest percentage of Juvenile Rheumatoid Arthritis patients belonged to 1115 years i.e. $75 \%$ but in contrast to other studies males were predominant in our study. This may be due to small sample size of Juvenile rheumatoid Arthritis patients in our study. Polyarticular form of disease had a greater incidence in our study than pauciarticular. Also male children in our society are paid more attention and they may be brought to seek medical care earlier and more frequently in comparison to female children. The disparity may be due to the late presentation or ignorance about the disease or may be the lack of accessibility of hospital, as most of the pauciarticular form being untreated, progressed to polyarticualr form.

Rheumatoid factor was negative in 14 (78\%) of 18 patients with Juvenile Rheumatoid Arthritis compatible to other studies but in contrast only 8 cases had positive Antinuclear Antibody positive.

The rare associated ocular manifestation with Rheumatoid Arthritis like multiple occlusive retinal arteritis, anterior ischemic optic neuropathy, orbital myositis, Brown's syndrome were not seen in our study.

Most of the patients of Rheumatoid Arthritis patient referred to us were mainly to rule out chloroquine toxicity 
involving the eye. Retinopathy from hydroxychloroquine and chloroquine toxicity have been extensively described and studied since its description in $1959^{38,39}$. David J. Browning, MD, PhD conducted a retrospective observational case study to report hydroxychloroquine and chloroquine retinopathy and consider screening for drug toxicity ${ }^{40}$. According to him new cases of hydroxychloroquine and chloroquine toxicity continue to develop in a screening environment and increased ophthalmologic attention to dosing, awareness of location and nature of early visual field defects, and traditional attention to presence or absence of maculopathy can reduce the incidence of this avoidable condition. In our study 25 patients out of 32 Rheumatoid Arthritis patients were on chloroquine but ocular toxicity was not noted

\section{REFERENCES}

1. Sudharshan S, Biswas J, Ganesh SK. Analysis of juvenile idiopathic arthritis associated uveitis in India over the last 16 years. Indian J Ophthalmol. 2007 May-Jun;55(3):199-202.

2. Copeman WSC, Scott JT. Copeman's Textbook of Rheumatic diseases. 5th ed. London: Churchil Livingstone; 1978. p 3-10.

3. Ruffing V, Bingham III OC. Rheumatoid Arthritis Signs and Symptoms [Internet], Baltimore (US), Johns Hopkins Arthritis center; updated 2012 Nov 28. Available from http://www.hopkinsarthritis.org/ arthritis-info/rheumatoid-arthritis/ra-symptoms/

4. Duke-Elder SWS. System of ophthalmology. 1st ed. Vol. 8. Maryland: Mosby c1965. Part 2, Disease of Outer eye; p.1106-8, and p.1008-61.

5. Albert MD, Miller WJ, Azar TD, Blodi AB. Albert \& Jakobiec's Principles and Practice of Ophthalmology, 2nd ed. Amsterdam (Netherlands): Elsevier Academic Press; 1994. Vol. 5, The eye and systemic disease, Childhood Arthritis and Anterior Uveitis; p. 4542-54.

6. Patel JS, Lundy CD. Ocular Manifestations of Autoimmune Disease. Am Fam Physician. 2002 Sep 15;66(6):991-8.

7. Reza D, Ocular Manifestation in Reumatoid Artritis [Internet]. 2010 [updated January 28, 2014; cited May 2010]. Available from: http://www.uptodate. com/patients/content/topic.do?topicKey= dd8hkD. r9fbU.v

8. Hogan MJ, Kimura SJ, Thygeson P: Signs and symptoms of uveitis: I. Anterior uveitis. Am J in any cases. This possibly may be due to the fact the chloroquine used was relatively for shorter duration in our patients in comparison to many other studies.

\section{CONCLUSION}

Ocular involvement are not uncommon in RA and JRA with a prevalence of $78.13 \%$ and $44.44 \%$ respectively noted in this study. Moreover, a significant number of cases are asymptomatic. Thus, a regular ophthalmologic evaluation should be done in all patients to ensure early identification of ocular involvement and thus to help alleviate the problems of visual impairment and blindness.

Ophthalmol. 1959;47:155

9. Abdel-Nasser AM, Rasker JJ, Valkenburg HA Epidemiological and clinical aspects relating to the variability of rheumatoid arthritis. Sem Arthritis Rheumatism. 1997;27:123-40.

10. McGavin DD, Williamson J, Forrester JV, Foulds WS, Buchanan WW, Dick WC, et al. Episcleritis and scleritis, A study of their clinical manifestations and association with rheumatoid arthritis. $\mathrm{Br} J$ Ophthalmol. 1976;60:192-26.

11. Kelley NW, Harris DE, Ruddy S, Sledge. Textbook of Rheumatology. 5th ed. Vol. 1 and 2. Philadelphia (US): WB Saunders; 1981;969-1207.

12. Albert MD, Miller WJ, Azar TD, Blodi AB. Albert \& Jakobiec's Principles and Practice of Ophthalmology. 2nd ed. Amsterdam (Netherlands): Elsevier Academic Press; 1994. Vol. 5, The eye and systemic disease, Adult Rheumatoid Arthritis; p. 4555-62 and p. 4735-36.

13. Reddy SC, Gupta SD, Jain IS, Deodhar SD. Ocular manifestations of rheumatoid arthritis. Indian $\mathrm{J}$ Ophthalmol. 1977; 25:20-6.

14. Dhakhawa K. Ocular manifestation in non-infective arthritis [MD thesis]. [Kathmandu]: BP Koirala Lions Centre for Ophthalmic Studies;2002.

15. Moss S.E. Prevalence and eye factor for dry syndrome. Arch Ophthalmol. 2000;118(9):1264-68.

16. Thompson M, Eadie S. Keratoconjuctivitis sicca and rheumatoid arthritis. Annal Rheumatic Dis. 1956;5:21.

17. Jain V, Singh S, Sharma A. Keratoconjunctivitis Sicca is not uncommon in children with juvenile 
rheumatoid arthritis. Rheumatol Int. 2001 May;20(4):159-2.

18. Kotaniemi KM, Salomaa PM, Sihto-Kauppi K, Säilä HM, Kauppi MJ. An evaluation of dry eye symptoms and signs in a cohort of children with juvenile idiopathic arthritis. Clin Ophthalmol. 2009 Feb;3:271-5.

19. Watson PG, Hayreh SS. Scleritis and episcleritis. Br J Ophthalmol. 1976;60(3):163-91.

20. Douglas AJ, Abdulbaki M, Dunn JP, Marsh JM. Episcleritis and Scleritis: Clinical Features and Treatment Results. Am J Ophthalmol. 2000;130:469-76.

21. McGavin DD, Williamson J, Forrester JV, Foulds WS, Buchanan WW, Dick WC, et al. Episcleritis and scleritis, A study of their clinical manifestations and association with rheumatoid arthritis. $\mathrm{Br} J$ Ophthalmol. 1976;60:192-226.

22. Kimura SJ, Hogan MJ, O'Conor GR, Epstein WV. Uveitis and joint diseases, clinical findings in 191 cases. Arch Ophthalmol. 1967 Mar;77:309-16.

23. Chylack LT Jr, Bienfang DC, Bellows AR, Stillman JS. The ocular manifestations of juvenile rheumatoid arthritis. Am J Ophthalmol. 1977 Mar; 20(2 Suppl):217-23.

24. Akpek EK, Uy HS,Christen W, Gurdal C, Foster CS. Severity of episcleritis and systemic disease association. Ophthalmology. 1999;106:729-1.

25. Squirrell DM, Winfield J, Amos RS. Peripheral ulcerative keratitis 'corneal melt' and rheumatoid arthritis: a case series. Rheumatology. 1999;38(12):1245-8.

26. Gudas PP Jr, Altman B, Nicholson DH, Green WR. Corneal perforations in Sjogren's syndrome. Arch Ophthalmol.1973;90:470-2.

27. Barth WF, Benson EL. Relapsing polychondritis, rheumatoid arthritis and blindness. Am J Ophthalmol.1968 Nov; 66(5):890-6.

28. Scharf $\mathrm{Y}$, Meyer E, Nahir M, Zonis S. Marginal melting of cornea in Rheumatoid Arthritis. Ann Ophthalmol. 1984 Oct;16,(10):924-6.

29. Feder RS, Krachmer JH. Conjunctival resection for the treatment of the rheumatoid corneal ulceration. Ophthalmology.1984;91:111-5.

30. Eiferman RA, Carothers DJ, Yankeelov JA Jr.
Peripheral rheumatoid ulceration and evidence for conjunctival collagenase production. Am J Ophthalomol. 1979;87:703-9.

31. Hazleman BL. Rheumatic disorders of the eye and the various structures involved. $\mathrm{Br} \mathrm{J}$ Rheumatol. 1996;35:258-68.

32. Rosenberg AM. Uveitis associated with childhood rheumatic diseases. Curr Opin Rheumatol. 2002;14:542-47.

33. Edelsten C, Lee V, Bentley RC, Kanski JJ, Graham ME. An evaluation of baseline risk factors predicting severity in juvenile idiopathic arthritis associated uveitis and other chronic anterior uveitis in early childhood. Br J Ophthalmol. 2002;86:51-6.

34. Key SN, Kimura SJ. Iridocyclitis associated with Juvenile Rheumatoid Arthritis. Arch Ophthalmol. 1977 Oct;95:1794-7.

35. Berk AT, Kocak N, Unsal E. Uveitis in Juvenile Rheumatoid Arthritis. Ocular Immunol Inflammation. 2001 Dec;9(4):243-51.

36. Säilä $H$, Kotaniemi K, Savolainen A, Kautiainen $H$, LeirisalonRepo M, Aho K. Uveitis in sibling pairs with juvenile idiopathic arthritis. Rheumatology. 2001;40(2):221-4.

37. Flynn HW Jr, davis JL, Culberston WW. Pars plana lensectomy and vitrectomy for complicated cataracts in Juvenile Rheumatoid Arthritis. Ophthalmology. 1988;95:1114-9.

38. Easterbrook M. Detection and prevention of maculopathy associated with antimalarial agents. Int Ophthalmol Clin 1999;39:49-57.

39. $\mathrm{Vu}$ L, Easterbrook M, Hovis JK. Detection of color vision defects in chloroquine retinopathy. Ophthalmology. 1999;106:1799-04.

40. Browning DJ. Hydroxychloroquine and Chloroquine Retinopathy: Screening for Drug Toxicity. Am J Ophthalmol. 2002 May 1;133:649-56. 